\title{
Permanent Magnet Bearingless Motors: Modelling, Design and Drive
}

\author{
B. Lapôtre, N. Takorabet, F. Meibody-Tabarb
}

\begin{abstract}
In this paper, the authors give a general description of bearingless machines and the origin of the ripples of the levitation force. Magnetic model using spectral analysis of the air-gap flux density is developed to identify the forces ripples and their origins. The authors propose two ways to suppress the force ripples. The first one can be performed during the design process of the machine while the second one can be applied with the supply via a control loop and an active harmonic suppression.
\end{abstract}

Index Terms-- Bearingless Motor, Harmonic suppression, Magnetic levitation, Permanent Magnet, Radial forces

\section{INTRODUCTION}

$\mathrm{M}$

ANY industrial applications require very high speed drives. Gas liquefaction, tool machines or turbomolecular pumps are some applications where the rotational speed exceeds ten thousands revolutions per minutes (rpm). These applications usually need magnetic bearings for the motors instead of classical ring or ball bearings, which avoid mechanical contact. This is useful for the power efficiency of the systems as well as for the life time. No mechanical contact means no friction losses and no wear of the bearings.

These magnetic levitation systems are complex and expensive but very well mastered by international manufacturers such as SKF, SCHAEFLER, ... Usually, a drive system using magnetic bearings include two radial bearings on each side of the machine and one axial bearing that allows the control of the position of the rotor in the 6 mechanical degrees of freedom (Fig. $1-\mathrm{a}$ ). These systems are often too long, so mechanical resonance issues appear when high rotational speeds are achieved.

A simplified study of the rotor dynamics shows that mechanical eigenmodes may coincide with magnetic excitation forces at limited rotational speeds which may damage the whole system. Several methods exist in order to avoid such problems. One of them consists in shortening the axial length of the mechanical system and/or reducing excitation forces. Figure 2 shows an illustration of this solution via the Campbel diagram. The reduction of the axial length $L_{z}$ avoids mechanical resonances at the operation speeds. The reduction of the axial length can be achieved by suppressing one of the two radial magnetic bearings as shown on Fig. 1-b and Fig. 1-c. Under these conditions, the motor must ensure its own magnetic levitation making it a "selfbearing" or "bearingless" motor.

B. Lapôtre is with SKF-Magnetics Mechatronics Saint Marcel 27950 France, (e-mail: blaise.lapotre@s2m.fr). N. Takorabet and F. Meibody-Tabar are with Université de Lorraine - GREEN, Vandoeuvre lès Nancy 54516 ,

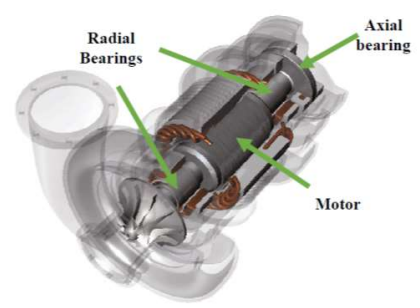

(a)

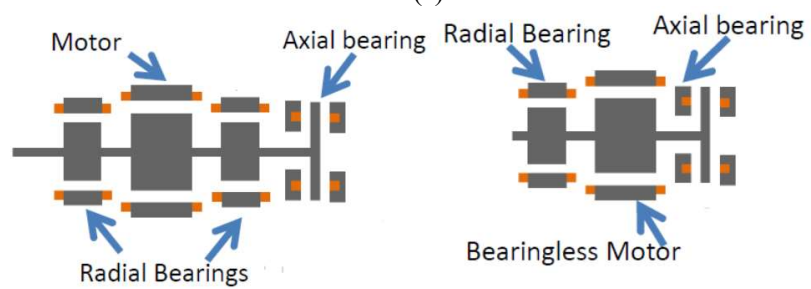

(b)

(c)

Fig. 1. From Magnetic bearing motor to Bearingless Motors a- Example of magnetic bearing motor for compressors b- Principle of classical Motor with 3 magnetic bearings c- Principle of Bearingless motor with 2 magnetic bearings
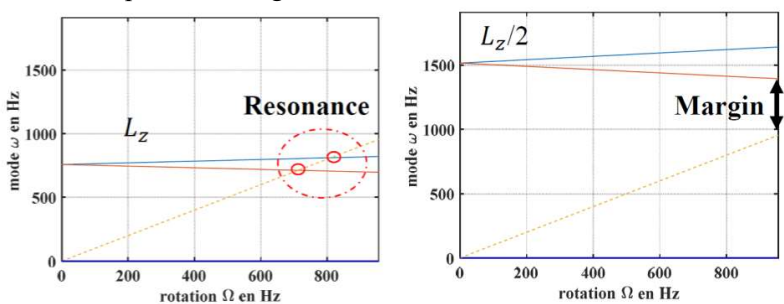

Fig. 2. Campbel diagram and mechanical interactions

a- High axial length an many force ripples

b- Rreducing axial length and suppression of force ripples

The other way consists in reducing all the ripples of the levitation forces in order to keep the levitation force constant. In other words, it is necessary to reduce the undulations of the levitation force similarly to the reduction of torque ripples for a rotating machine.

Bearingless machines have been introduced several decades ago thanks to some recognized professors such as A. Chiba who has studied many topologies of these special machines for different applications [1-5]. Different topologies of Bearingless machines have been proposed and studied for different applications: induction machines, switched reluctance machines, and permanent magnet machines. [6-13]. Our contribution to this topic aims to develop magnetic models which allow the identification of the sources of force ripples and to find a way to suppress them through design [14- 
17]. Another contribution is to develop an external model taking into account these phenomena and to contribute to the suppression of force ripples through control. In this article, these two approaches are presented and validated by experimental tests on a permanent magnet bearingless machine.

\section{SOME MODELING ASPECTS}

The principle of the bearingless motor consists in obtaining in the same machine a torque ensuring the rotation and a force that ensures the levitation of the rotor. If the distribution of the field in the air gap is known, the calculation of the forces acting on the rotor can be carried out by using the Maxwell stress tensor on a closed path $\Gamma$ in the air-gap.

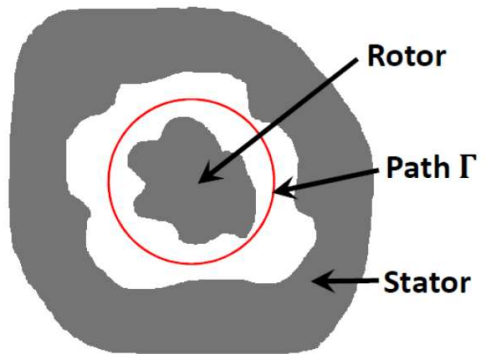

Fig. 3. Principle of torque and force calculation with Maxwell stress tensor

The radial forces acting on the rotor can be expressed in an orthonormal basis $x-y$ and can be written in the form:

$$
\begin{aligned}
& F_{x, m}=R L_{z} \int_{0}^{2 \pi}\left[\sigma_{n} \cos m_{s}-\sigma_{t} \sin m \theta_{s}\right] d \theta_{s} \\
& F_{y, m}=R L_{z} \int_{0}^{2 \pi}\left[\sigma_{n} \sin m \theta_{s}+\sigma_{t} \cos m \theta_{s}\right] d \theta_{s}
\end{aligned}
$$

where: $\sigma_{n}=\frac{1}{2 \mu_{0}}\left(B_{n}^{2}-B_{t}^{2}\right)$ and $\sigma_{t}=\frac{1}{2 \mu_{0}} 2 B_{t} B_{n}$ are the normal and tangential magnetic stresses on each point of coordinate $\theta_{s}$ of the path $\Gamma$.

In the case of electric machines, magnetic levitation consists in using the forces of index $m=1$ in the equation above and therefore, levitation forces are due to the interaction of two harmonics of successive ranks of the air-gap flux density. The torque of the machine is only due to the tangential stress $\sigma_{t}$, which involves the product of the normal and tangential components of the air-gap flux density.

Therefore, harmonics of identical ranks of the normal and tangential components of distribution of the flux density give birth to the electromagnetic torque while the harmonics of successive ranks give birth to the levitation force.

Thus, in a bearingless machine, it is necessary to have a distribution of the flux density in the air gap with at least $p$ and $p+1$ pole pairs in order to ensure both the torque and the levitation force. Figure 3 shows a very simple case of a simultaneous presence of harmonics $p=1$ and $p=2$ allowing the two purposes. Presence of several pairs of harmonics of successive ranks also creates levitating forces as the presence of harmonics of higher ranks of $B_{t}$ and $B_{n}$ creates constant additional torques in the conventional rotating machines.
The torque ripples arise when the dynamic problem is introduced because it involves rotational speeds of the different travelling waves that are not necessarily identical. The same reasoning can be adapted to the levitation force and its ripples. Hence, it is interesting to study the effects of time variation on the behavior of the levitation forces and their directions.

The topology of the machine has a great influence on force undulations. So, in the case of permanent magnet bearingless machines, it is more convenient to have a rotor with surface mounted magnets with 2 poles $(=1)$ and to provide the stator with a polyphase stator winding generating magnetic flux density with 2 poles $(p=1)$ and 4 poles $(p=2)$.

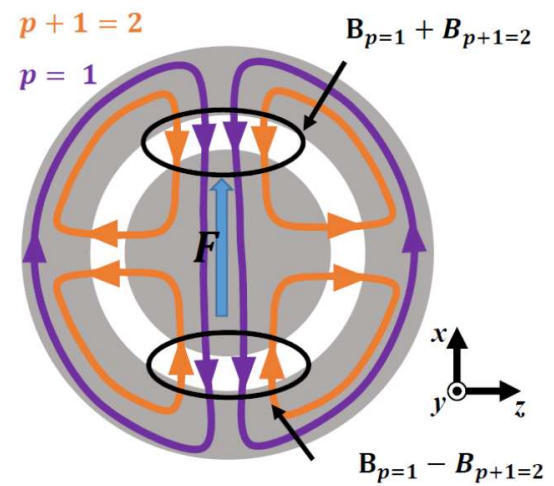

Fig. 4. Principle of force generation in Bearingless machines

A $q$-phase winding with $q$ concentric coils is considered on the stator armature. This winding can be supplied and create a $p$-pole flux density in the air-gap. The generalized Concordia transformation can be applied to obtain different two-phase equivalent systems and/or homoplar systems, yields:

$$
\left[i_{d 1} i_{q 1} i_{d 2} i_{q 2} \ldots i_{h 1} i_{h 2}\right]=P(-\theta) T_{q q}^{t}\left[i_{a} i_{b} i_{c} \ldots i_{q}\right]
$$

where $T_{q q}^{t}$ is the generalized Concordia transformation matrix of order $q$ and $P(\theta)$ is a specific rotation matrix adapted to the considered polyphase system with $\theta$ the electrical angle related to the rotor position. Application of these transformations to the variables of a $q$-phase winding allows considering the $q$-phase winding equivalent of several 2-phase equivalent windings $\left(d_{1} q_{1}, d_{2} q_{2}, \ldots\right)$ as well as one single-phase equivalent winding $h_{1}$ ( $q$ an odd number) or two single-phase equivalent windings $h_{1}$ and $h_{2}$ ( $q$ an even number).

In a $q$-phase PM motor with rotor surface mounted of $p$ pole pairs, the current components $i_{d 1}$ and $i_{q 1}$ represent the currents of the first ("main") equivalent 2-phase winding which create an equivalent current sheet denoted by the system $I_{d q 1}$ with $p$ pole pairs (its other space harmonics have the ranks of $m q \pm p$ ). When the PM motor is supplied by sinusoidal currents of pulsation $\omega=\dot{\theta}$, forming an balanced $q$-phase sinusoidal system, only the main 2-phase winding generates the torque. The current components $i_{d 2}$ and $i_{q 2}$ represent the currents of the second equivalent 2-phase winding which create an equivalent current sheet denoted by the system $I_{d q 2}$ with $p+1$ pole pairs (its other space 
harmonics have the ranks of $m q \pm(p+1))$. Then the supply of the machine phases in a way that $i_{d 2}$ and $i_{q 2}$ have non zero values allows generating a radial force which can be adjusted by these current components. The other current components $\left(i_{d 3} i_{q 3}, i_{d 4} i_{q 4}, \ldots\right)$, represent the currents of the other equivalent 2-phase windings which create the equivalent current sheets denoted by the systems $\left(I_{d q 3}, I_{d q 4}, \ldots\right)$ having numbers of pole pairs greater than $p+1$. These current components create the systems that often perturb the torque and force generation. Then the adapted phase number for bearingless PM machines can be 5 or 6 . With a Y-connected 5-phase PM machine we have 5 current components, the zero sequence (homopolar) current component is zero $\left(i_{h 1}=0\right)$, the torque is controlled by the components $i_{d 1}$ and $i_{q 1}$ and the radial force by $i_{d 2}$ and $i_{q 2}$ that will be denoted by $i_{x}$ and $i_{y}$ in the flowing. For a 6 -phase PM machine we have 6 current components. If the phase windings are realized around 6 stator teeth and the rotor magnets has one pole pair (Figure 5), it is possible to define two $\mathrm{Y}$-connected 3-phase windings respectively with the odd phases $1,3,5\left(i_{1}+i_{3}+i_{5}=0\right)$ and the even phases $2,4,6\left(i_{2}+i_{4}+i_{6}=0\right)$. In this case, both the zero sequence (homopolar) current component $i_{h 1}$ and the quasi zero sequence (quasi homopolar) current component $i_{h 2}$ are zero. Then, the torque is controlled by the components $i_{d 1}$ and $i_{q 1}$ and the radial force by $i_{d 2}$ and $i_{q 2}\left(i_{x}\right.$ and $\left.i_{y}\right)$. Therefore:

$$
\left[\begin{array}{l}
i_{d 1} \\
i_{q 1} \\
i_{d 2} \\
i_{q 2}
\end{array}\right]=\left[\begin{array}{l}
i_{d} \\
i_{q} \\
i_{x} \\
i_{y}
\end{array}\right]=P_{44}(-\theta) \cdot T_{64}^{t} \cdot\left[\begin{array}{l}
i_{1} \\
i_{2} \\
i_{3} \\
i_{4} \\
i_{5} \\
i_{6}
\end{array}\right]
$$

with: $T_{64}^{t}$ the reduced concordia transformation excluding homoplar components and $P_{44}(-\theta)$ a specific rotation matrix defined by :

$$
P_{44}(-\theta)=\left[\begin{array}{cccc}
\cos \theta & \sin \theta & 0 & 0 \\
-\sin \theta & \cos \theta & 0 & 0 \\
0 & 0 & \cos \theta & \sin \theta \\
0 & 0 & -\sin \theta & \cos \theta
\end{array}\right]
$$

It is also possible to arrange two separate 3 -phase windings generating fields of the two polarities $(p=1$ and $p+1=2)$ and supplied with sinusoidal currents of frequencies $f_{1}$ and $f_{2}$, respectively. Each stator winding generates a fundamental harmonic and a set of space harmonics. These harmonics generate traveling waves in the positive and negative directions according to the well-known polyphase system theory. The velocities and directions of these waves depend on the supply frequencies $f_{1}$ and $f_{2}$. It has been shown in previous papers [17] that the two windings must be supplied with sinusoidal currents at the same frequency. Thus the interaction of the $1^{\text {st }}$ harmonic of the stator field with the rotor magnets of polarity $p=1$ induces the constant torque. Moreover, the interaction of the main harmonic $p=2$ of the stator winding with the rotor magnets rotating at the speed $\Omega=2 \pi f_{1}$ gives a force in a constant direction if the frequencies of the two 3-phase currents are equal: $f_{2}=f_{1}$.

The different field harmonics due to the two stator windings or systems lead to many interactions that must be highlighted and quantified. In order to determine correctly these different interactions, one must express the different fields in the air-gap as a function of their sources and in terms of Fourier series.

$$
\left\{\begin{array}{l}
B_{n}\left(\theta_{s}\right)=\frac{1}{2} \sum_{k, s} B_{k, s}^{n} e^{j k \theta_{s}}+B_{k, s}^{n *} e^{-j k \theta_{s}} \\
B_{t}\left(\theta_{s}\right)=\frac{1}{2} \sum_{k, s} B_{k, s}^{t} e^{j k \theta_{s}}+B_{k, s}^{t *} e^{-j k \theta_{s}}
\end{array}\right.
$$

where $k$ denotes the harmonic rank and $s$ denotes the source of the field. In the case of the studied machine, $s$ takes three values:

$s=1: 2$-pole source or winding $(p=1)$ on the stator

$s=2: 4$-pole source or winding $(p=2)$ on the stator

$s=3: 2$-pole magnets $(p=1)$ on the rotor

The use of the definition of levitating forces (1) and this representation of normal and tangential flux density components allows us to express the force components $F_{x}$ and $F_{y}$ along the axes $x$ and $y$ in the form (a sum of different elementary forces generated by the interactions of successive ranks flux density harmonics a sum of different contributions of many harmonic interactions of successive ranks [14].

$$
\left\{\begin{array}{l}
F_{x}=\frac{R L_{z} \pi}{2 \mu_{0}} \sum_{s, \sigma, k} F_{k, s, \sigma}^{x} \\
F_{y}=\frac{r \cdot L_{z} \pi}{2 \mu_{0}} \sum_{s, \sigma, k} F_{k, s, \sigma}^{y}
\end{array}\right.
$$

where the subscripts $s$ and $\sigma$ refer to the three field sources defined above. The subscript $k$ refers to the harmonic rank which implies the interaction of the harmonics $k$ and $k+1$ of the air gap fields. $F_{k, s, \sigma}^{x}\left(\right.$ or $F_{k, S, \sigma}^{y}$ ) is the $x$ (or $y$ ) component of an elementary force generated by the interaction of the flux density harmonic of rank $k$ created by the field source $s$ and the flux density harmonic of rank $k+1$ created by the field source $\sigma$. We notice that $s$ and $\sigma$ can be different field sources or the same field source.

The analysis of the different air-gap field components and the influence of their positions (stator or rotor) makes it possible to simplify the general expressions of these forces to obtain a general shape as follows:

$$
\begin{aligned}
& F_{k, s, \sigma}^{x}=K_{k, s, \sigma} \cos \left(\theta_{s, k}^{n}-\theta_{\sigma, k+1}^{n}\right) \\
& F_{k, s, \sigma}^{y}=K_{k, s, \sigma} \sin \left(\theta_{s, k}^{n}-\theta_{\sigma, k+1}^{n}\right)
\end{aligned}
$$

The amplitude $K_{k, s, \sigma}$ of the harmonic $k$ of the force has several expressions according to the positions of the source. The pulsation of the force depends on the difference of the pulsations of the rotating fields in mutual interaction. This is expressed by the difference of the phases shift $\left(\theta_{s, k}^{n}-\theta_{\sigma, k+1}^{n}\right)$ given in equation 7 . The subscripts $k, s, \sigma$ can represent one of the three sources: the two stator supplies and rotor magnets.

By this way, it is possible to identify the contribution of each interaction of the field components in terms of amplitude and frequency of the force for each position of the rotor. Then, the expression of the force components can be easily determined. 


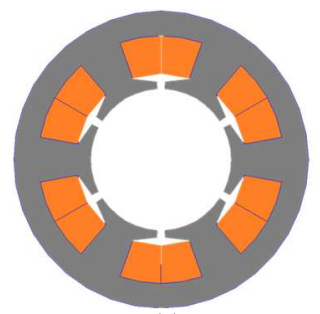

(a)

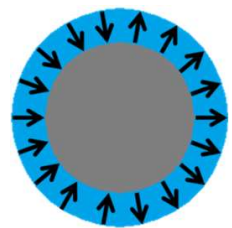

(b)

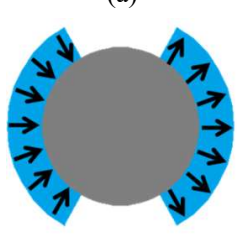

(c)

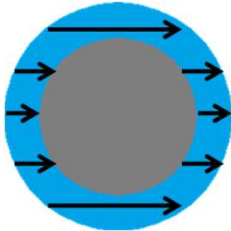

(d)
Fig. 5. Different studied topologies of the stator and rotor a- 6 Slot - 6-phase stator

$\mathrm{b}$ - radial magnetization of rotor magnets of $180^{\circ} \mathrm{span}$ c - radial magnetization of rotor magnets of $120^{\circ} \mathrm{span}$ $\mathrm{d}$ - parallel magnetization of rotor magnets

\section{DESIGN BASED FORCE RIPPLE REDUCTION}

The developed model allows determining the levitation force for any topology and takes into account the space harmonics of the magnetic field and the corresponding force ripples. In this section the cases of 6-phase motors (Fig.5-a) with radial magnetized (Fig. 5-b) or parallel magnetized (Fig. 5 -d) full pitch magnets and $120^{\circ}$ radial magnetized rotor (Fig. 5-c) are presented and discussed. For each case, we determine the force acting on the rotor over a whole period.

\section{A. Flux density harmonics \\ 1) Stator}

Nevertheless, the polyphase windings generate high order harmonics and their ranks depend on the pole number and phase number. These harmonics can be significant and have to be taken into account and in order to consider their contributions to the torque and the levitation force.

The "main" system $I_{d q I}$ generates harmonics of order: $m q \pm p$ where $m$ is a given integer whereas the system $I_{d q 2}$, generates harmonics of order: $m q \pm 2 p$. The stator winding generates harmonics of the flux density presented in Tab. I where the nature of the corresponding waves is specified by "F" for forward harmonics and "B" for backward harmonics.

The stator winding composed by 6 concentrated coils which are supplied by a 6-leg inverter. The stator winding is supplied by the superposition of two six-phase currents corresponding to the systems $I_{d q 1}$ and $I_{d q 2}$ :

$$
\left\{\begin{array}{l}
\left.i_{k, 1}=I 1 \cos 2 \pi f_{1} t+\varphi_{1}+\frac{(k-1) \pi}{6 \text { or } 5}\right) \\
i_{k, 2}=I 2 \cos \left(2 \pi f_{2} t+\varphi_{2}+\frac{2(k-1) \pi}{6 \text { or } 5}\right)
\end{array}\right.
$$

$I 1, I 2, f_{1}, f_{2}, \varphi_{1}$, and $\varphi_{2}$ represent the amplitudes, frequencies and the phases of the two systems respectively. According to the polyphase winding theory, the two systems generate forward harmonics of the air-gap flux density of rank
$6 m+1$ and $6 m+2$ and backward harmonics of rank $6 m-$ 1 and $6 m-2$. (Fig. 5-a to Fig.5-d) These travelling waves have different mechanical velocities but they present the electrical pulsations $\omega_{1}=2 \pi f_{1}$ and $\omega_{2}=2 \pi f_{2}$, when they are expressed in a fixe frame.

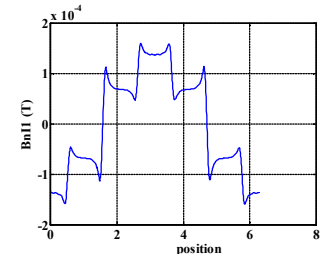

(a)

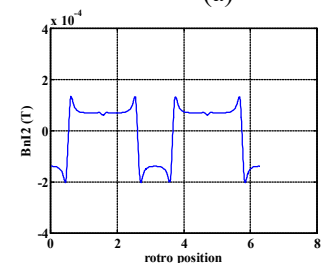

(c)

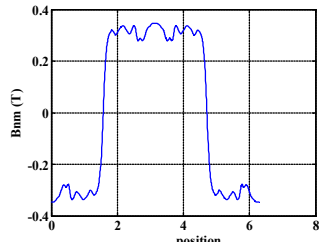

(e)

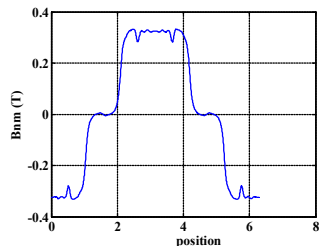

(g)

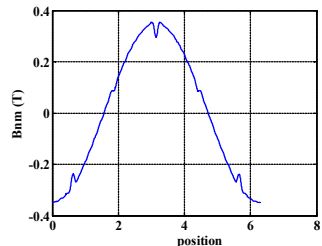

(i)

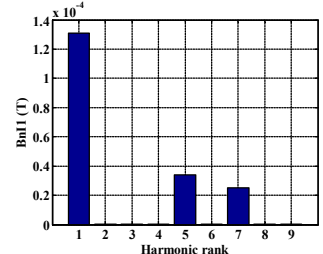

(b)

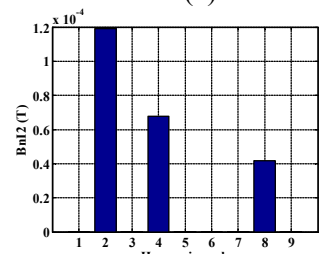

(d)

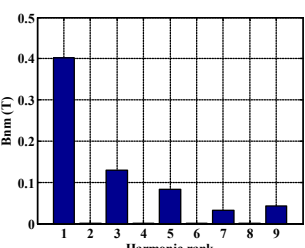

(f)

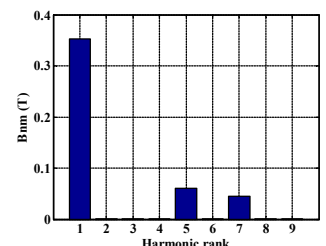

(h)

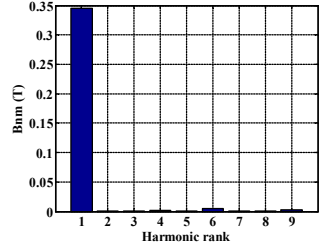

(j)
Fig. 6. Radial component of flux density and its harmonics content: a-b : current system $I_{d q 1}$ in 6 phase stator c-d : current system $I_{d q 2}$ in 6 phase stator e-f : radial magnetization of rotor magnets of $180^{\circ} \mathrm{span}$ $\mathrm{g}-\mathrm{h}$ : radial magnetization of rotor magnets of $120^{\circ} \mathrm{span}$ $\mathrm{i}-\mathrm{j}$ : parallel magnetization of rotor magnets of $180^{\circ}$ span

\section{2) Rotor}

The field harmonics generated by the rotor depend on its topology (surface mounted magnets, surface inserted magnets, buried magnets, ...). In the case of rotor surface mounted magnets, different cases are identified: Parallel magnetization or Radial magnetization of the magnets span of $180^{\circ}$ or $120^{\circ}$. With parallel magnetization, the distribution of the air-gap flux density, generated only by the rotor magnets, is almost sinusoidal (Fig.5-i, Fig.5-j). In the second case (Radial magnetization), when the magnets span is $180^{\circ}$, the distribution of the air-gap flux density contains all odd harmonics. (Fig. 5-e, Fig.5-f). When the magnets span is $120^{\circ}$, 
the distribution of the air-gap flux density contains all odd harmonics, except the ones of rank multiple of $3(3,9 \ldots)$ (Fig. 5-g, Fig.5-h). All these field harmonics are static in rotor reference frame, but they are rotating in the same direction with respect to the stator reference frame (considered as "F: Forward"). The field space harmonic of rank $k$ has an electrical pulsation of $k \omega$ in the stator reference frame. The interactions of these harmonics must be taken into account in the calculation of the force components in order to evaluate more precisely the levitation force and the electromagnetic torque (Table I).

In the following section, the analysis of force waveforms and harmonics is discussed for different rotor topologies. For each case, a table of all source of magnetic field is set up to identify the interactions and the elementary forces. In this tables (Tab. II to Tab. IV) the different pairs of harmonics which interact and generate radial force components are highlighted. As it has been discussed, it is established that to have a constant torque, the electric pulsation of the $I_{d q 1}$ system and the mechanical pulsation must be equal $\omega=\omega_{1}$. In order to obtain a constant levitation force it is necessary to have $\omega_{1}=\omega_{2}$.

\section{B. Analysis of force spectral components}

Fig. 6-a. shows the force components $F_{x}$ and $F_{y}$ obtained by the proposed analytical model and by a full FEM computation in the case of a parallel magnetized rotor. There is an excellent accordance between the two models and the force waveforms are similar. The spectral analysis of the force waveforms is shown on Fig. 6-b for both $F_{x}$ and $F_{y}$ components. This spectral analysis allows the identification of the interaction between the different harmonics of the flux density.

For example, in Table II, the interaction of the $4^{\text {th }}$ field harmonic (of pulsation $-\omega$ ) due to the current system $I_{2}$ and the $3^{\text {rd }}$ field harmonic (of pulsation $+3 \omega$ ) due to the magnets, produces the $4^{\text {th }}$ harmonic of the force in a positive sequence. Henceforth, the following notation $\left(4 I_{d q 2},-3_{\text {mag }} \Rightarrow 4_{\text {force }}\right)$ will be adopted to describe such interactions.

\section{1) Radial magnetized rotor with $180^{\circ}$ magnets span:}

The constant force components are due to all couples of harmonics which have the same frequency: $\left(1_{\text {mag }}, 2_{\text {Idq2 }} \Rightarrow\right.$ $\left.0_{\text {force }}\right),\left(1 I_{d q 1}, 2_{\text {Idq2 }} \Rightarrow 0_{\text {force }}\right),\left(4 I_{d q 2}, 5 I_{d q 1} \Rightarrow 0_{\text {force }}\right)$ and $\left(7 I_{d q 1}, 8 I_{d q 1} \Rightarrow 0_{\text {force }}\right)$. The force ripples result from all the interactions of fields with different frequencies. Figure 6 shows the corresponding force waveforms and their spectral analysis.

The interaction $\left(4 I_{d q 2}, 3_{\text {mag }} \Rightarrow 4_{\text {force }}\right)$ provides the $4^{\text {th }}$ harmonic of the force while the interaction $\left(2 I_{d q 2}, 3_{\text {mag }} \Rightarrow\right.$ $-2_{\text {force }}$ ) generates the second harmonic of the force. Furthermore, it can be seen that the harmonics of higher ranks may have several origins. For example, the interactions $\left(4 I_{d q 2}, 5_{\text {mag }} \Rightarrow-6_{\text {force }}\right)$ and $\left(8 I_{d q 2}, 7_{\text {mag }} \Rightarrow 6_{\text {force }}\right)$ lead to the $6^{\text {th }}$ harmonic of force. These harmonics have the same norm in $x$ and $y$ axes because the force comes from two elementary forces in opposite sequences.
TABLE I

REPRESENTATION OF THE MMF AND ROTOR HARMONICS MMF Harmonics

\begin{tabular}{|c|c|c|c|c|c|c|c|c|c|c|c|c|}
\cline { 2 - 13 } \multicolumn{1}{c|}{} & 1 & 2 & 3 & 4 & 5 & 6 & 7 & 8 & 9 & 10 & 11 & 12 \\
\hline $\mathrm{I}_{1}$ & $\mathrm{~F}$ & & & & $\mathrm{~B}$ & & $\mathrm{~F}$ & & & & $\mathrm{~B}$ & \\
\hline $\mathrm{I}_{2}$ & & $\mathrm{~F}$ & & $\mathrm{~B}$ & & & & $\mathrm{~F}$ & & $\mathrm{~B}$ & & \\
\hline & 1 & 2 & 3 & 4 & 5 & 6 & 7 & 8 & 9 & 10 & 11 \\
\hline Parallel & $\mathrm{F}$ & & & & & & & & & & \\
\hline Radial $120^{\circ}$ & $\mathrm{F}$ & & & & $\mathrm{F}$ & & $\mathrm{F}$ & & & & $\mathrm{F}$ \\
\hline Radial $180^{\circ}$ & $\mathrm{F}$ & & $\mathrm{F}$ & & $\mathrm{F}$ & & $\mathrm{F}$ & & $\mathrm{F}$ & & $\mathrm{F}$ \\
\hline
\end{tabular}

TABLE II: HARMONIC PULSATIONS FOR 6 PHASE STATOR AND RADIAL MAGNTIZATION OF ROTOR MAGNETS

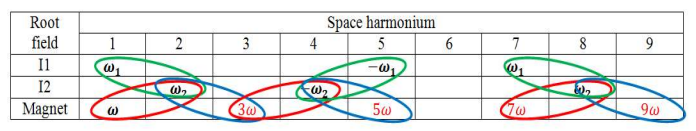

TABLE III: HARMONIC PULSATIONS FOR 6 PHASE STATOR AND RADIAL MAGNETIZATION OF ROTOR $120^{\circ}$ MAGNETS SPAN

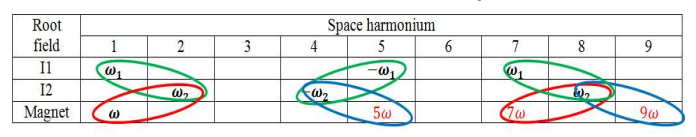

TABLE IV: HARMONIC PULSATION FOR 6 PHASE STATOR AND RADIAL MAGNETIZATION OF ROTOR $180^{\circ}$ MAGNETS SPAN

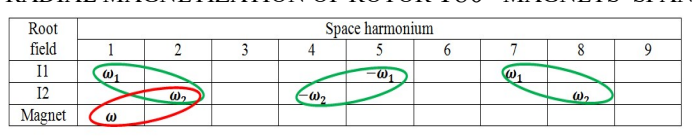

2) Radial magnetized rotor with $120^{\circ}$ magnets span

Table III shows the interaction of elementary forces in this case and Fig. 7 shows the force waveforms. As seen in the previous section, the use of rotor magnets of $120^{\circ}$ span with a radial magnetization eliminates the $3^{\text {rd }}$ harmonic of the air-gap flux density. In this case, flux density harmonics generating constant forces are: $\left(1_{\text {mag }}, 2 I_{d q 2} \Rightarrow 0_{\text {force }}\right)\left(1 I_{d q 1}, 2 I_{d q 2} \Rightarrow\right.$ $\left.0_{\text {force }}\right),\left(4 I_{d q 2}, 5 I_{d q 1} \Rightarrow 0_{\text {force }}\right),\left(7 I_{d q 1}, 8 I_{d q 2} \Rightarrow 0_{\text {force }}\right)$. Flux density harmonics also generate force harmonics but many elementary interactions are eliminated thanks to the suppression of the $3^{\text {rd }}$ harmonic of magnet flux density. However, some flux density harmonics remain and generate force harmonics:

$\left(4 I_{d q 2}, 5_{\text {mag }} \Rightarrow-6_{\text {force }}\right)$ and $\left(8 I_{d q 2}, 7_{\text {mag }} \Rightarrow 6_{\text {force }}\right)$. These two force components are not problematic because they have small amplitudes and high frequencies. In these conditions, the levitation can be ensured without high level of mechanical resonance.

\section{3) Parallel magnetized rotor}

The best solution to get rid of all force harmonics is to choose a rotor magnet with parallel magnetization (Fig. 5-d). In this configuration, only the following constant force components are generated (Tab. IV): $\left(1_{\text {mag }}, 2 I_{d q 2} \Rightarrow 0_{\text {force }}\right)$ $\left(1 I_{d q 1}, 2 I_{d q 2} \Rightarrow 0_{\text {force }}\right), \quad\left(4 I_{d q 2}, 5 I_{d q 1} \Rightarrow 0_{\text {force }}\right) \quad$ and $\left(7 I_{d q 1}, 8 I_{d q 2} \Rightarrow 0_{\text {force }}\right)$. The total force waveform is then presented in Fig. 8. The force ripples are totally eliminated. 


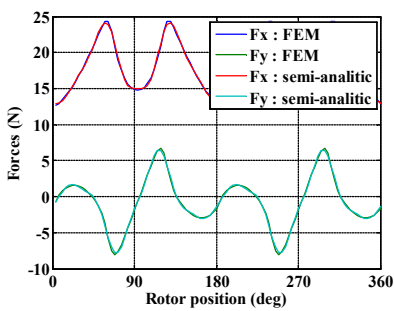

(a)

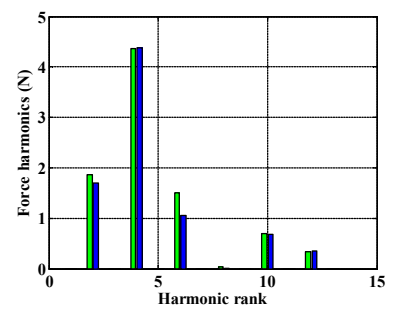

(b)
Fig.6. Force waveforms (a) and its spectral components (b). (radial magnetized magnets of $180^{\circ} \mathrm{span}$ )
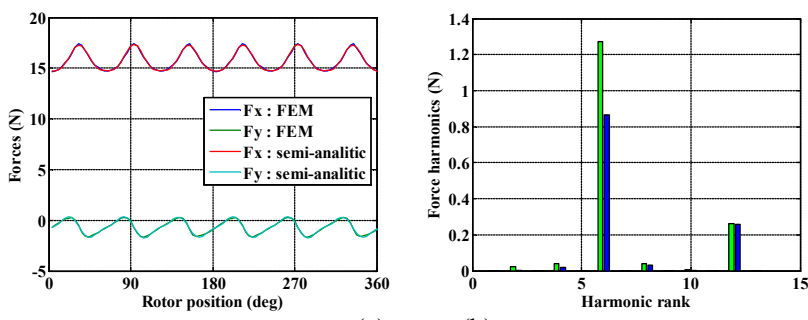

(a)

Fig. 7. Force waveforms (a) and its spectral components (b). (radial magnetized magnets of $120^{\circ} \mathrm{span}$ )
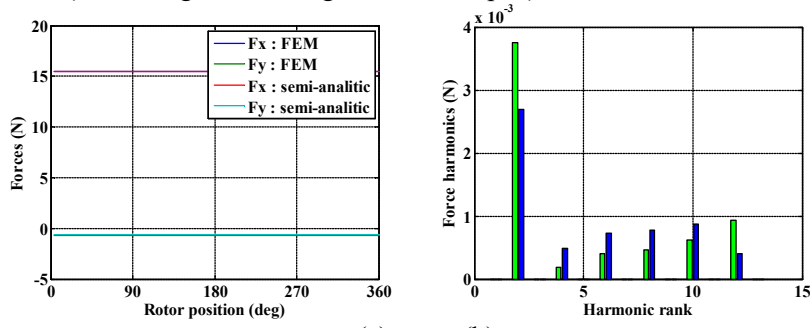

(a)

(b)

Fig. 8. : Force waveforms (a) and its spectral components (b). (Parallel magnetized magnets of $180^{\circ}$ span)

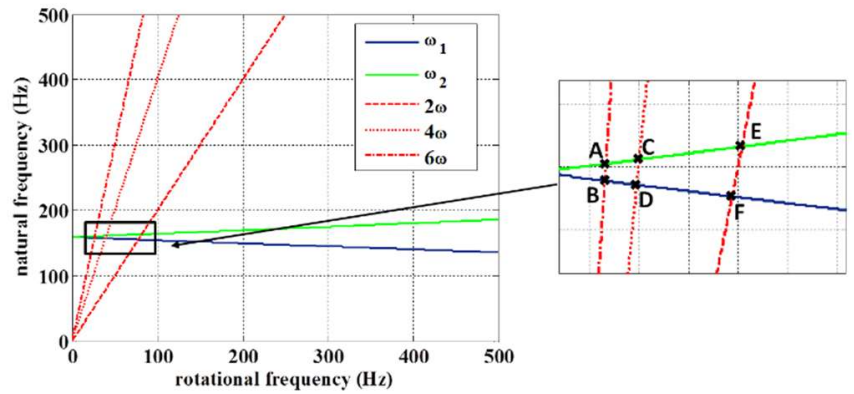

Fig. 9. Campbell diagram with the parasitic harmonic forces

\section{Discussion about mechanical consequences}

The model of the elementary forces can determine the direction of the force (positive or negative sequences). This information helps the designer to find the critical frequencies which occurs when the pulsation of a given perturbation coincides with a natural frequency. The Campbell diagram of Fig. 9 shows all interactions. The different critical frequencies for each interaction are observed:

$$
\begin{aligned}
& \left(2 I_{d q 2}, 3_{\text {mag }} \Rightarrow-2_{\text {force }}\right) \text { in } \mathrm{F}, \\
& \left(4 I_{d q 2}, 3_{\text {mag }} \Rightarrow 4_{\text {force }}\right) \text { in } \mathrm{C}, \\
& \left(4 I_{d q 2}, 5_{\text {mag }} \Rightarrow-6_{\text {force }}\right) \text { in } \mathrm{B}, \\
& \left(8 I_{d q 2}, 7_{\text {mag }} \Rightarrow 6_{\text {force }}\right) \text { in } \mathrm{A} .
\end{aligned}
$$

These critical frequencies are more problematic when the perturbation amplitude is high and its frequency is low. Therefore the most problematic frequencies are located in $\mathrm{F}$ and $\mathrm{C}$ on the Campbell diagram.

The proposed model gives more useful informations concerning force harmonic components (their amplitudes, the fact that they are forward or backward). This allows the prediction of the influence of force harmonics on the rotor dynamics. Then, the compromise between rotor dynamics and industrial constraints allows choosing the most adapted topology for bearingless motors.

\section{CONTROL BASED FORCE RIPPLE ELIMINATION}

The suppression of force ripples and the stabilization of the drive of bearingless machines can be performed with an appropriate control strategy. Many contributions have been proposed for this purpose [18-19]. The method proposed in this section uses the harmonic field model combined with a closed control loop aiming to suppress the harmonics separately [20].

Based on the expressions of radial force components $\left(F_{x}\right.$ and $F_{y}$ ) in bearingless PM motors, the radial force given in equations (6) and (7) can be expressed in its complex form as a sum of the complex elementary forces:

with:

$$
F=\sum_{s, \sigma, m} F_{k, s, \sigma}
$$

$$
F_{k, s, \sigma}=K_{k, s, \sigma} e^{i\left(\theta_{n, s, k}-\theta_{n, \sigma, k+1}\right)}
$$

The coefficient $K_{m, s, \sigma}$ can be written in the form of the product of two coefficients depending on the magnetic field sources.

$$
K_{m, s, \sigma}=C_{m, s}(s) \cdot C_{m+1, \sigma}(\sigma)
$$

The case of a bearingless PM motor having a rotor magnet of one pole pair $(p=1)$ with radial magnetization and a 6-phase stator winding as in section III is considered. To generate a constant force component, the current pulsation $\omega_{2}$ must be equal to the rotational speed $\omega=\dot{\theta}$, where $\theta$ is the rotor angular position. Under this condition, force harmonics of rank 2 and 4 exist due to the harmonics of flux density generated by stator currents and rotor magnets. The expression of these force harmonics are given by:

$$
\begin{aligned}
& F_{2}=C_{2, I_{x y}} I_{x y} e^{i\left(\theta+\varphi_{2, I_{x y}}\right)} C_{3, m} e^{i\left(-3 \theta+\varphi_{3, m}\right)} \\
& F_{4}=C_{3, m} e^{i\left(3 \theta+\varphi_{3, m}\right)} C_{4, I_{2}} I_{x y} e^{i\left(\theta+\varphi_{4, I_{x y}}\right)}
\end{aligned}
$$

where:

$I_{x y}=I_{x}+i I_{y}$, with $I_{x}$ and $I_{y}$ are the constant levitation current components controlling respectively the force components $F_{x}$ and $F_{y}$.

- $\quad \varphi_{2, I_{x y}}, \varphi_{3, \text { magnet }}$ and $\varphi_{4, I_{x y}}$ are the phases of the flux density harmonics of ranks 2, 3 and 4 generated by either the levitation stator currents or the rotor magnets.

- $\quad C_{2, I_{x y}}, C_{3, \text { magnet }}$ and $C_{4, I_{x y}}$ are the constants related to the machine geometrical parameters. 
In the next part, equations (12) and (13) are used in the control algorithm to compensate the force harmonics.

\section{A. 3. Active compensation algorithm of force harmonics}

To remove a force harmonic of rank $n$, a control method, based on injecting levitation current harmonics proportional to the force harmonics, is proposed, as shown in Fig. 10 and Fig. 11. In equation (9), each force harmonic is the product of a constant part depending on the machine geometrical parameters, and the complex levitation current $\left(I_{x}+i I_{y}\right)$. The determination of the constant part is based on the fact that each force harmonic generates a periodic displacement (with the same frequency) of the rotor, characterized by the position $(x, y)$ of the rotor axis . First, the amplitude of each displacement harmonic of $(x y)$ is determined by applying a rotation matrix $P(-n \theta)$ followed by low pass filters. Then, the constant part is directly obtained by using PI correctors (Fig. 11). The dependence on the levitation current is taken into account by the product of the constant part by the reference of the levitation current $\left(I_{x}^{*}+i I_{y}^{*}\right)$. Finally, the components of levitation current harmonics to compensate the force harmonics are deduced by applying a rotational matrix $P(n \theta)$ and the results are added to $I_{x y}^{*}=I_{x}^{*}+i I_{y}^{*}$. This process should be repeated for the compensation of each force harmonic.

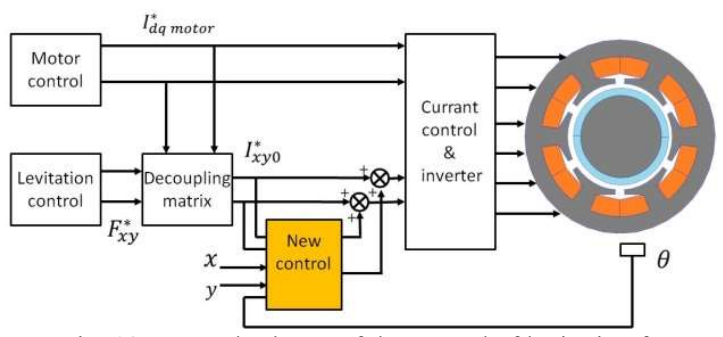

Fig. 10. General scheme of the control of levitation force

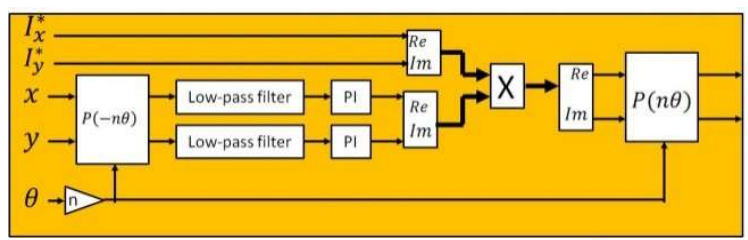

Fig. 11. Principle of force ripples elimination using a control loop

This control strategy is then implemented on a prototype of 6-phase PM bearingless motor. A first test is performed without the proposed controller at a low speed in order to highlight the rotor displacement $x$ and $y$ generated by the force harmonics. The results are shown in terms of orbital position $(x, y)$ of the rotor axis. Fig. 12-a shows the case of initial orbital position without any harmonic suppression. When applying the active compensation of the force $2^{\text {nd }}$ harmonic, the orbital position of the rotor is slightly modified (Fig. 12-b) because the amplitude of this harmonic is too low. The suppression of the $4^{\text {th }}$ harmonic of the force leads to the orbital shown on Fig. 12-c. It can be clearly seen that the ripples of pulsation $4 \omega$ are suppressed. The suppression of both $2^{\text {nd }}$ and $4^{\text {th }}$ harmonics gives the orbital of Fig. 12-d.

With this method, and thanks to the magnetic model, it is possible to control the harmonic content of the levitation force with the supply. These results prove the efficiency of the proposed force control method in eliminating the perturbations due to the considered force harmonics on the quality of rotor levitation.

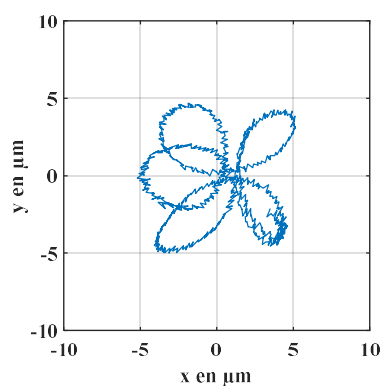

(a) Initial orbit

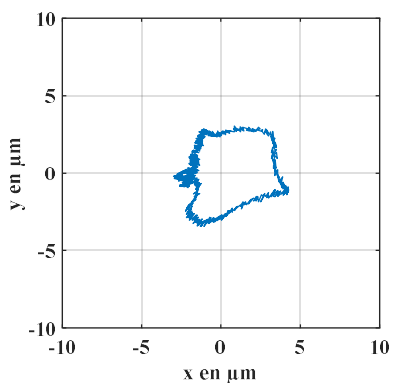

(a) Suppressing $F_{4}$

Suppressing both $F_{2}$ and $F_{4}$

Fig. 12. Orbital position with and without force harmonic suppression

\section{CONCLUSION}

The authors present the general architectures of bearingless motors and propose a spectral approach of the modeling of field interactions in the air-gap. The model is based on the spectral decomposition of the fields in the air-gap due to different sources (magnets and currents). The spectral formulation of the radial forces is performed with Maxwell stress tensor. It allows the calculation of different interactions between field harmonics and predicts the harmonic content of the force waveforms. Such a model is useful for the designer, which may specify the undesirable field harmonics before starting the design.

The reduction of force ripples is discussed and performed in two ways. The first one can be applied in the design level where the topology of the machine is defined. The second one can be performed with the control. It needs an external model and an identification process that allows to define additional currents in the supply.

\section{REFERENCES}

[1] A. Chiba, T. Fukao, O. Ichikawa, M. Oshima, M. Takemoto and D. G. Dorrell, Magnetic Bearings and Bearingless Drives, Oxford: Elsevier, 2005.

[2] A. Chiba, D. Power et M. Rahman, «Characteristics of a bearingless induction motor», IEEE Trans. Magn., vol. 27, no. 16, pp. 5199-5201, 1991.

[3] M. Oshima, S. Miyazawa, T. Deido, A. Chiba, F. Nakamura and T. Fukao, «Characteristics of a permanent magnet type bearingless motor» IEEE Transactions on Industry Applications, vol. 32, no. 12, pp. 363370,1996

[4] K. Inagaki, A. Chiba, M. Rahman and T. Fukao, «Performance characteristics of inset-type permanent magnet bearingless motor 
drives», IEEE Power Engineering Society Winter Meeting, 2000, vol. 1, no. 1, ISBN: 0-7803-5935-6, 2000.

[5] A. Chiba, T. Deido, T. Fukao and M. Rahman, "An analysis of bearingless AC motors",, IEEE Transactions on Energy Conversion, vol. 9, ISSN : 0885-8969, 1994.

[6] K. Raggl, T. Nussbaumer and J. W. Kolar, "Comparison of separated and combined winding concepts for bearingless centrifugal pumps", $J$. Power Electron, vol. 9, march 2009.

[7] W-R. Canders, D. Hulsmann, "Analysis and Classification of Bearingless machines with symmetric 3-phase concentrated windings", 19th Int. Conf. on Electric Machines ICEM 2010, Roma, Italy.

[8] S. T and A. Binder, "Design and Evaluation of a $60000 \mathrm{rpm}$ Permanent Magnet Bearingless High Speed Motor", PEDS '07 Bangkok, 2007.

[9] Z. Liu, Z. Deng, J. Cai, Y. Wu, S. Wang, "Optimal design of a bearingless switched reluctance motor", Int. Conf. Applied Superconductivity and Electromagnetic Devices ASEMD, pp. 241-245, 2009.

[10] T. Baumgartner, R. M. Burkart and J. W. Kolar, «Analysis and Design of a $300-\mathrm{W} 500000-\mathrm{r} / \mathrm{min}$ Slotless Self-Bearing Permanent-Magnet Motor,», IEEE Transactions on Industrial Electronics, vol. 61, no. 18, pp. 4326-4336, 2014.

[11] M. Kang, J. Huang, J. Yang, H. Jiang, "Analysis and experiment of a 6 phase bearignless induction motor", Proceedings on Electrical Machines and Systems. pp. 990-994, 2008.

[12] D. Steinert, T. Nussbaumer, J. Kolar "Concept of a $150 \mathrm{krpm}$ bearingless slotless disc drive with combined windings", Proceedings on Electric Machines \& Drives Conference (IEMDC), pp. 311-318, 2013

[13] M.T. Bartholet, S. Silber, T. Nussbaumer, J. W. Kolar, "Performance Investigation of Two-, Three-, and Four-Phase Bearingless Slice Motor configurations", 7th IEEE Int. Conf. on Power Electronics and Drive Systems PEDS'07, november 2007, Bangkok

[14] B. Lapôtre, N. Takorabet, F. Meibody-Tabar, R. Lateb, J. DaSilva, New Model of Radial Forces determination in Bearingless Motors, IEEE Trans. Magn., vol. 51, no. 3, march 2015

[15] B. Lapôtre, N. Takorabet, F. Meibody-Tabar, R. Lateb, J. DaSilva, Radial Forces modeling for bearingless motors based on analyze of field origins, Proc. of the Institution of Mech. Eng., Part I: Journal of Systems and Control Eng., July 2015

[16] B. Lapôtre, N. Takorabet, F. Meibody-Tabar, R. Lateb, J. DaSilva, Spectral modeling of force ripples in permanent magnet bearingless motors, The International Journal for Computation and Mathematics in Electrical and Electronic Engineering (COMPEL), vol. 35, No. 5, 2016
[17] B. Lapôtre, N. Takorabet, F. Meibody-Tabar, R. Lateb, J. DaSilva, On the use of spectral analysis of air-gap flux density in Permanent Magnet Bearingless Motors, ICEM'2014, pp. 591 - 597, Berlin 2014

[18] A. Chiba, R. Furuichi, Y. Aikawa, K. Shimada, Y. Takamoto and T. Fukao, "Stable operation of induction-type bearingless motors under loaded conditions", IEEE Transactions on Industry Applications, vol. 33, ISSN : 0093-9994, Jul/Aug 1997.

[19] F. Zürcher, T. Nussbaumer and J. W. Kolar, «Principles of magnetic levitation force and motor torque generation by superposition of harmonics in bearingless brushless motors», IECON '09., Porto, 2009.

[20] B. Lapôtre, B. NahidMobarakeh, N. Takorabet, F. Meibody-Tabar, R. Lateb, J. DaSilva, Active suppression of structural force harmonics in PM bearingless motors, 15th International Symposium on Magnetic Bearings ISMB 2016, Kitakyushu, Japan 2016, 3-6 August

\section{BIOGRAPHIES}

Blaise Lapôtre received the Engineer degree ENSEM, Nancy, France, and master's degree in electrical engineering from University Nancy I, France, in 2012. Re received his $\mathrm{PhD}$ from Université de Lorraine in 2016 .He is currently R\&D Engineer at S2M-SKF, France. His main research activities deal with architectures and control of bearingless motor.

Noureddine Takorabet received the master's degree in electrical engineering from University Nancy I, France, in 1994 and PhD from INPL in 1996. He received the "Habilitation à Diriger des Recherches" degree in 2007 from the Institut National Polytechnique de Lorraine (INPL, Nancy, France). $\mathrm{He}$ is currently Professor at Lorraine University, member of the laboratory GREEN-ENSEM, Nancy, France. His main research activities deal with electromagnetic devices modelling and optimisation. In particular, he is interested in electromechanical conversion.

Farid Meibody-Tabar received the Engineer degree at ENSEM, Nancy, France, in 1982, the Ph.D. degree in 1986 and the "Habilitation à Diriger des Recherches" degree in 2000 from the Institut National Polytechnique de Lorraine (INPL, Nancy, France). Since 2000 he has been engaged as Professor at INPL. His research activities in GREEN, deal with architectures and control of electrical machines supplied by static converters 